NASA Technical Memorandum 102028

AIAA-89-2534

\title{
New Hypersonic Facility Capability at NASA Lewis Research Center
}

\author{
(UASA-TH-102028) WEW EXPEFSCAIC FACILITY \\ CAEABILIII AI NASA LELIS RESEAECE CEATER \\ (AASA. Levis Rescarch Center) 16 pCSCL 14B
}

Jeffrey E. Haas, Roger Chamberlin, and John H. Dicus

Lewis Research Center

Cleveland, Ohio

Prepared for the

25th Joint Propulsion Conference

cosponsored by the AIAA, ASME, SAE, and ASEE

Monterey, California July 10-12, 1989 


\section{NEW HYPERSONIC FACILITY CAPABILITY AT NASA LEWIS RESEARCH CENTER}

Jeffrey E. Haas, Roger Chamberlin, and John H. Dicus

National Aeronautics and Space Administration

Lewis Research Center

Cleveland, Ohio 44135

\section{Abstract}

Four facility activities are underway at NASA Lewis to develop new hypersonic propulsion test capability. Two of these efforts consist of upgrades to existing operational facilities. The other two activities will reactivate facilities that have been in a standby condition for over 15 years. This paper discusses these four activities and describes the new test facilities NASA Lewis will have in place to support evolving highspeed research programs.

\section{Introduction}

As a result of the renewed interest in hypersonic flight motivated primarily by the National Aerospaceplane Program, activity is underway within the government, industry, and the academe to develop expanded hypersonic test capability. These efforts consist of building new facilities as well as reactivating and upgrading existing facilities. Some of the existing facilities have been maintained in various conditions of standby over the past 15 to 20 years and require significant repair, rehabilitation, and/or upgrade in order to bring them back into operational service. At NASA Lewis Research Center a commitment has been made to develop new hypersonic propulsion system test capabilities. Four separate facility activities are currently underway to provide this test capability. Two of the projects involve upgrades of operational facilities. They consist of an expansion of the 1 - by I-ft supersonic wind tunnel to provide Mach 6 aerodynamic test capability and modifications to the Propulsion System Laboratory for Mach 6 directconnect capability. The third activity is the reactivation of the Hypersonic Tunnel Facility (HTF) at NASA Lewis' Plum Brook Station to restore its originally-designed Mach 5, 6, and 7 propulsion test capability. The fourth activity is the planned reconstruction of the $2 \mathrm{l}-\mathrm{in}$. Hypersonic Wind Tunnel (HWT) which was dismantled and shipped from the Jet Propulsion Laboratory in 1988. Once reconstructed, the 2l-in. HWT will provide a Mach 4 to 11 aerodynamic test capability.

This paper will summarize these four activities and describe the new test facilities that NASA Lewis will have in place to support evolving highspeed/hypersonic research programs.

\section{Facility Descriptions}

\section{Introduction}

The following sections summarize each of the four activities at NASA Lewis underway to develop new high-speed (hypersonic) facility capability. Figure 1 illustrates how the se activities will augment existing NASA Lewis capability. Before these activities commenced the 10- by 10-ft Supersonic Wind Tunnel (SWT) was the largest, highest speed operational propulsion facility at NASA Lewis. The 10- by 10-ft SWT is capable of a maximum Mach number of 3.5. The 1- by 1-ft SWT had a maximum
Mach number limit of 4.0 before its upgrade was initiated. After all of the new activities are completed NASA Lewis will have four facilities capable of Mach 6 and higher through a combination of free-jet, direct-connect, and wind tunnel. Brief descriptions of most of the existing facilities shown in Fig. 1 are found in Refs. 1 and 2 .

\section{1 - by 1-Ft Supersonic Wind Tunnel}

The 1-by 1-ft Supersonic wind Tunnel ( $1 \times 1$ SWT) was constructed in the early 1950's as a continuous-flow, aerodynamic tunnel that utilizes interchangeable two-dimensional nozzle blocks to achieve discrete Mach number settings over a range from 1.3 to 4.0 . The facility was used initially for basic inlet research and concept screening. Also, a considerable amount of testing was performed on configurations for missiles, launch vehicles, and space vehicles, including scaled portions of the Mercury capsules. The facility was removed from service in 1950 and remained inactive for 11 years. It was reactivated and operated in 1972 and 1973, and was retired from service for another 6 years. It was reactivated again in 1980 and has remained operational. The work in the early 1980's concentrated on basic research of boundary layers and shock/boundary layer interactions. Much of this work was oriented toward university graduate studies. In the last several years testing emphasis has changed significantly. The $1 \times 1$ SWT has begun to play a key role in various major programs of national interest such as the National Aerospaceplane Program (NASP). It has become one of the most heavily scheduled facilities at NASA Lewis used primarily for subscale inlet and nozzle component testing and also to obtain data for validating newly-developed computational fluid dynamics flow codes. A schematic of the facility is shown in Fig. 2 and a photograph of the test section is shown in Fig. 3. The $|x|$ SWT is located within the NASA Lewis Engine Research Building. Air is supplied to the tunnel from the NASA Lewis central air system at either 40 or 150 psig. Downstream of the diffuser the facility is connected to the central exhaust system which produces a minimum pressure of about 2 psia. Existing nozzle blocks are available to permit operation at Mach numbers of $1.3,1.6,2.0,2.5,3.0,3.5$, and 4.0 . The nozzle blocks are stored on the floor below the facility and are raised into place with a hydraulic lift. Nozzle blocks can be changed and the facility returned to operation in approximately $20 \mathrm{~min}$. A range of Reynolds numbers is possible by varying the air supply pressure. The original performance range is shown in Fig. 4 and indicates a maximum unit Reynolds number of about $11.5 \mathrm{milli}$ ion per foot.

Because of the growing interest in high-speed flight an opportunity arose to expand the $1 \times 1$ SWT operating envelope to enhance support of these high-speed programs. Design changes were undertaken to upgrade the $1 \times 1$ SWT to Mach 6 . This was accomplished by adding an electric heater in the air supply line and fabricating new nozzle blocks 
For Mach 5.5 and 6.0. Mach 6 is about the maximum Mach number that can be achieved with a facility of this size that utilizes two-dimensional nozzle blocks. The gap at the throat is very small and higher Mach numbers would not be practical. There is an existing nozzle block for Mach 5.0. However. because the facility originally had no provisions for heating the inlet air, the temperature drop from the expansion to Mach 5 was too large and i quefaction began to occur in the test section. io achieve higher Mach numbers a $650-\mathrm{kW}$ electric heater is being added in the air supply line. This is shown in dashed lines in Fig. 2. The air supply piping has been modified to include the heater so that either heated air enters the upstream surge tank or varying amounts of heated air can be mixed with unheated air upstream of the surge tank to provide a range of temperatures. Temperatures between 560 and $1110^{\circ} \mathrm{R}$ will be achievable. This permits an increase in the Reynolds number range at the lower Mach numbers as shown on Fig. 4. Also shown are the Reynclds number iimits achievable at the Mach 5.0, 5.5, and 6.0 conditions. At these higher Mach numbers the maximum unit Reynolds number will be abcut 10 million per foot. The higher temperature air resulting from the heater addition required a water spray system to be installed in the diffuser section. This system lowers the air temperature to no more than $610^{\circ} \mathrm{R}$ before discharging into the contral exhaust system. The upgrade modifications are nearing completion and the facility is expected to oe at full operational capability by August 1989 .

\section{Propulsion Systems Laboratory}

The Propulsion Systems Laboratory (PSL) is NASA's only altitude engine test facility. PSL is capable of testing large-scale airbreathing engine systems under simulated altitude, temperature, and pressure conditions. PSL became operational in 1973. A schematic of PSL is shown in Fig. 5. The facility consists of two test chambers, designated PSL-3 and PSL-4. Eoth chambers are $39 \mathrm{ft}$ in length and $24 \mathrm{ft}$ in diameter. Each test leg consists of an inlet section, test chamber, and exhaust section. The two exhaust sections are joined to a common exhaust plenum chamber, primary cooler, and spray cooler. Both chambers contain thrust beds with a maximum thrust limit of $100000 \mathrm{lb}$. Each test leg is connected to the NASA Lewis central 40 and 150 psig compressed air systems. The air can be heated to $1560^{\circ} \mathrm{R}$ or cooled to $410^{\circ} \mathrm{R}$. Air is exhausted into the central exhaust system. As a direct-connect altitude simulation facility the operazing envelope extends to $70000 \mathrm{ft}$ altitude and a Mach rumber of 3 .

In 1985 a jecision was made to modify PSL-4 to prowide a Mach 3 to 6 direct-connect test capability to support advanced airbreathing hypersonic propulsion research. Modifications were required to the inlet air supply and conditioning system to provide the high pressure and temperature. The modifications were incorporated in such a way that PSL-4 can be returned to its original configuration. The facility design requirements were provided from plans at that time to test an air-turbo-ramjet proof-of-concept demonstrator. A schematic of PSL-4 showing the modifications is shown in Fig. 6 . New combustion air piping was added to isolate the test cell inlet plenum from the high pressure air and to provide airflow measurement through a system of venturi flowmeters. The inlet air system provides a range of airflows up to $30 \mathrm{ib} / \mathrm{sec}$ over a range of pressure from 1 to 100 psia. Elevated inlet temperature is provided by a vitiating gaseous-hydrogen-fueled air-heater which allows control of temperature from 560 to $3460^{\circ} \mathrm{R}$. The air heater is a four-burner design with each burner being supplied by a separate, controllable inlet air supply. A gaseous oxygen injection system provides make-up oxygen to compensate for the combustion process. Downstream of the heater a chamber provides settling time and allows mixing of the inlet air. The test article draws air from the settling chamber through a bellmouth iniet duct system. The design envelope for the Mach 6 modification is shown in Fig. 7 superimposed on the original capability. Correct iniet stagnation conditions are provided to the inlet of a test articie in direct-connect mode up to Mach 6 within a range of dynamic pressure between 100 and 1000 psf.

A new high-energy propellant transfer and supply system was provided to supply gaseous hydrogen and gaseous oxygen to the inlet air neater and the test article. Gaseous hydrogen and gaseous oxygen are available to the test article at 2.75 and $3.0 \mathrm{lb} / \mathrm{sec}$, respectively, at a pressure of 1000 psig. The allowable run time in the Mach 3 to 6 range is determined by the propellant storage capacity. At maximum design propellant transfer rates, 30 to $60 \mathrm{~min}$ of run time are achieved. In addition, kerosene fuels and high pressure methane are available to the test article. Because of the addition of gaseous hydrogen to PSL, a number of safety measures needed to be incorporated. There was particular concern in unburned hydrogen passing into the central exhaust system equipment. Hydrogen detectors and dilution air were added at various places in the test chamber and in the exhaust system. Hydrogen/air torches were also provided in the test cell and exhaust system to flare any unburned hydrogen. Because of hydrogen flame propagation 1 imits, the test article exhaust pressure is maintained at 5 psia and above to assure that the flare torches will consume any unburned hydrogen. Assuming that the test article exit nozzle is choked, this exhaust pressure limitation does not significantly impact the flight simulation since the correct inlet stagnation conditions are set.

By the fall of 1988 the Mach 3 to 5 modifications were completed and checkouts initiated. The checkouts were performed using a hollow pipe (designated the "hot-pipe") which incorporated a calibrated Supersonic Tunnel Association nozzle at the exit. The "hot-pipe" test program demonstrated operational status of all facility modifications and allowed tailoring to provide the desired flow quality at the test article inlet. Thrust and airflow accuracies approached the design goal of 1 percent. Radial and circumferential variations of total temperature and total pressure at the test article inlet also approached the design goal of 1 percent.

\section{Hypersonic Tunnel Facility}

The Hypersonic Tunnel Facility (HTF) is a nonvitiated, blowdown, free-jet facility capable of testing large-scale hypersonic engines and/or components at Mach numbers of 5,6 , and 7 . HTF is located at NASA Lewis' Plum Brock Station approximately 50 miles west of Cleveland. The facility is 
capable of true temperature, altitude, and air composition simulation. Figure 8 shows an aerial view and Fig. 9 shows a schematic of HTF. The heart of HTF is a gaseous nitrogen induction storage heater that is designed to provide maximum heater exit flow conditions of about $130 \mathrm{lb} / \mathrm{sec}, 1200 \mathrm{psia}$, and $5000^{\circ} \mathrm{R}$. Downstream of the heater cold gaseous oxygen and cold gaseous nitrogen are injected into the high temperature gaseous stream to provide a simulated air composition and the correct inlet stagnation temperature to the nozzle inlet. There are interchangeable Mach 5, 6, and 7 nozzles, each having an exit diameter of 42 in. The inviscid core diameter of the three nozzles is about $2 \mathrm{ft}$. The test chamber is $25 \mathrm{ft}$ in diameter and $20 \mathrm{ft}$ high. The test chamber is evacuated using a single-stage steam ejector. A diffuser is used to provide additional pumping capability to achieve a maximum $120000 \mathrm{ft}$ altitude condition. The test chamber contains a model injection system and a thrust mount assembly. The free-jet length of the test chamber can be adjusted by translating the diffuser. The maximum length is about $10 \mathrm{ft}$. Five gaseous hydrogen roadable tube trailer stations are available for engine fuel. A gaseous hydrogen pebble bed resistance heater is capable of heating $2.5 \mathrm{lb} / \mathrm{sec}$ from ambient temperature to $1660^{\circ} \mathrm{R}$ for $90 \mathrm{sec}$. The design operating envelope for HTF is shown in Fig. 10. Altitude is plotted against Mach number. Lines of nozzle inlet stagnation temperature and stagnation pressure are also shown. The design operating envelope spans from 68000 to $120000 \mathrm{ft}$ altitude, 70 to 1200 psia nozzle inlet stagnation pressure, and 2200 to $4200^{\circ} \mathrm{R}$ nozzle inlet stagnation temperature. The operating envelope is constrained by the limiting factors shown. Over the range of flow conditions, run times from $42 \mathrm{sec}$ to about $5 \mathrm{~min}$ are achievable.

HTF originally became operational in 1971. From January 1972 to May 1974 the Aerothermodynamic Integration Model (AIM) version of the Hypersonic Research Engine (HRE) was installed, checked out, and tested. Overall, there were 52 tests with an accumulated total test time of about $112 \mathrm{~min}$. Approximately $30 \mathrm{~min}$ of this time was at Mach 7 , although true temperature simulation of $3700^{\circ} \mathrm{R}$ at Mach 7 was not achieved due to degradation of the carbon insulating felt in the induction storage heater. This problem was not resolved at the time due to priority demands to complete the test program. At the completion of the HRE test program HTF was placed in a standby condition. The key stimulus for considering reactivation of HTF was the evolvement of the NASP. Due to its being inactive for almost 13 years, a detalied reactivation study was conducted in 1986. The thrust of this study was to determine the cost estimate to reactivate HTF to its original design operating capabilities. Facility modifications to resolve several previous operating problems were included in the cost estimate. Prime interest was placed in ensuring reliable induction storage heater performance. Two other concerns were recertification of all of the facility pressure vessels and resolution of a minor model erosion problem that occurred during testing of the HRE. Reference 3 describes in more detail the capabilities and history of HTF and the results of the reactivation study. In 1987, the results of the HTF reactivation study were integrated into the NASA Wind Tunnel Revitalization Program. A FY 1990 Construction of Facilities (COF) discrete project will provide $\$ 4.1$ million of reactivation funding. Since 1987, low-level reactivation activities have been underway to address some of the identified long-lead items. Two key activities have been the replacement of the induction storage heater graphite blocks and felt material and the return of a $5000 \mathrm{ps} i \mathrm{~g}, 726000$ standard cubic feet gaseous nitrogen railcar that was on loan to the Stennis space center. This railcar is the supply vessel for the induction heater. Based on current schedules all reactivation activities should be completed by early 1991 An additional 6 months of integrated systems checkout and facility calibration is planned. HTF would then be operational by about July 1991.

\section{2l-in. Hypersonic Wind Tunne?}

The 21-in. Hypersonic Wind Tunnel (HWT) is a continuous-flow, variable-density, aerodynamic tunnel that utilizes a two-dimensional flexible nozzie to provide an infinite choice of test section Mach numbers from 4 to 11 . Figure 17 is a photograph of the nozzle and test section looking upstream. Figure 12 shows a schematic view of the HWT. The tunnel is closed-loop and contains its own fourstage compressor plant. The compressors provide a maximum 650 psia to the supply section. The supply air temperature can be varied up to $1810^{\circ} \mathrm{R}$ using an electric heater. The test section Mach number is established by shimming the nozzle throat to the required dimension and then adjusting the upper and lower walls from the throat to the nozzle exit to provide smooth continuous surfaces. The adjustments are manually performed using hydraulic actuators. This procedure for accurately contouring the nozzle walls provides high-quality flow to the test model. The test section is 21 in. wide at the downstream end and 15 to $28 \mathrm{in}$. high depending on the Mach number being set. The test section length is approximately $6 \mathrm{ft}$. The test section sidewalls are removable providing easy access to the test model. A crescent-type model support system provides remote control of the model angle-ofattack over a $30^{\circ}$ range. A diffuser provides pumping capability to allow simulation of a test section altitude range from 85000 to $220000 \mathrm{ft}$. The diffuser throat is remotely actuated during operation to aid in normal shock positioning. A tunnel aftercooler reduces the air temperature to about $560^{\circ} \mathrm{R}$ before the air is routed back to the compressors.

The 21-in. HWT became operational at the jet Propulsion Laboratory (JPL) in 1959. The HWT was used in support of a variety of Department of Defense and NASA missile and space venicle programs. Basic research programs were conducted to investigate turbulent boundary layer development and laminar boundary layer tripping and stability. The HWT ceased operation in 1975 and was left in a standby condition. Interest was generated in 1987 in reactivating the HWT to support the NASP. However, reactivation of the HWT was not pursued and consideration was given to moving the HWT to another NASA center. NASA Lewis aggressively pursued obtaining the HWT for three primary reasons. First, with NASA Lewis' efforts to expand its aerorautics propulsion research program to higher Mach numbers the HWT becomes an excellent aerodynamic test facility to conduct sub-scale model experiments and high-quality validation experiments for computational fluid dynamics flow code development. Secondly, the HWT is in good condition and possesses excellent capabilities - large Mach and Reynolds number ranges coupled with excellent flow 
quality. The operating envelope as shown in

Fig. 13. Thirdly, acquisition of the HWT is considered to be timely and cost effective - the replacement cost is projected to be over three times the rehabilitation cost. As a result of its advocacy efforts NASA Lewis was given approval and funding to dismantle and ship the tunnel components. In the last half of 1988 the entire tunnel loop, including drive compressors, was dismantled and shipped. The components presently are being stored at NASA Lewis' Plum Brook Station until funding is approved to reconstruct the tunnel at NASA Lewis. Currently, a FY 91 CoF project is being advocated to provide the funding to reconstruct the HWT. The cost estimate is approximately $\$ 11$ million. Over the past several months a tunnel site study was conducted and a site selected. Work is currently underway to conduct the detailed engineering studies and designs required to support the Cof project. Based on current schedules, the 21-in. HWT would become operational by mid-1993.

\section{Concluding Remarks}

This paper was intended to provide a brief summary of activities underway at NASA Lewis
Research Center to develop new high-speed (hypersonic) facility capability to support a variety of evolving research programs. While none of these new facility capabilities may be singularly unique within the industry, they collectively enable NASA Lewis to significantly expand its in-house research activities in the high-speed area and at the same time provide quality test facilities for cooperative programs with industry, academe, and other government agencies.

\section{References}

1. Penaranda, F.E. and Freda, M.S., "Aeronautical Facilities Catalogue, Vol. I - Wind Tunnels." NASA RP-1132, 1985.

2. Penaranda, F.E. and Freda, M.S., "Aeronautical Facilities Catalogue, Voi. II - Airbreathing Propulsion and Flight Simulators," NASA RP-1133, 1985.

3. Haas, J.E., "Reactivation Study for NASA Lewis Research Center's Hypersonic Tunnel Facility," AIAA Paper 87-1886, June 1987 (NASA TM-89918). 

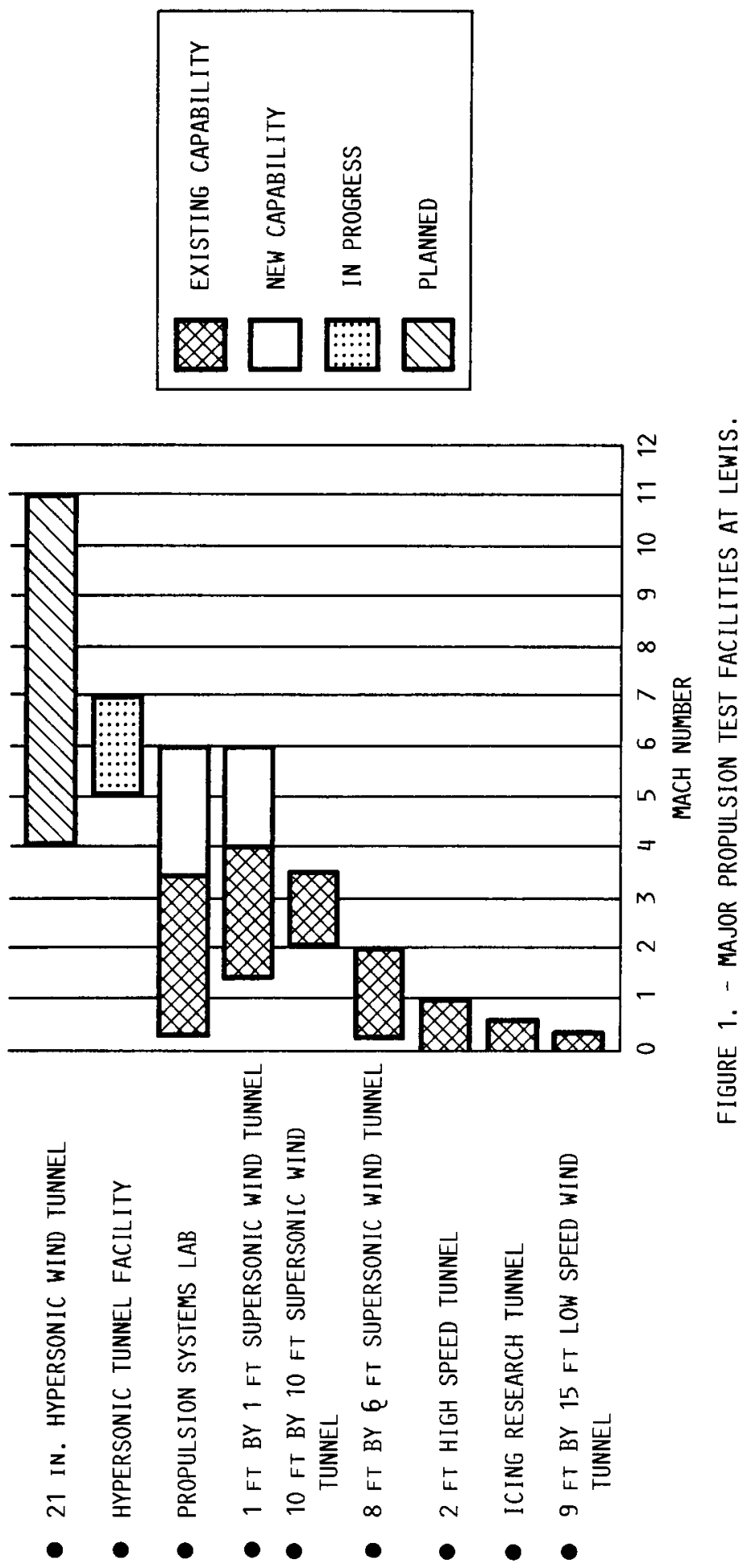


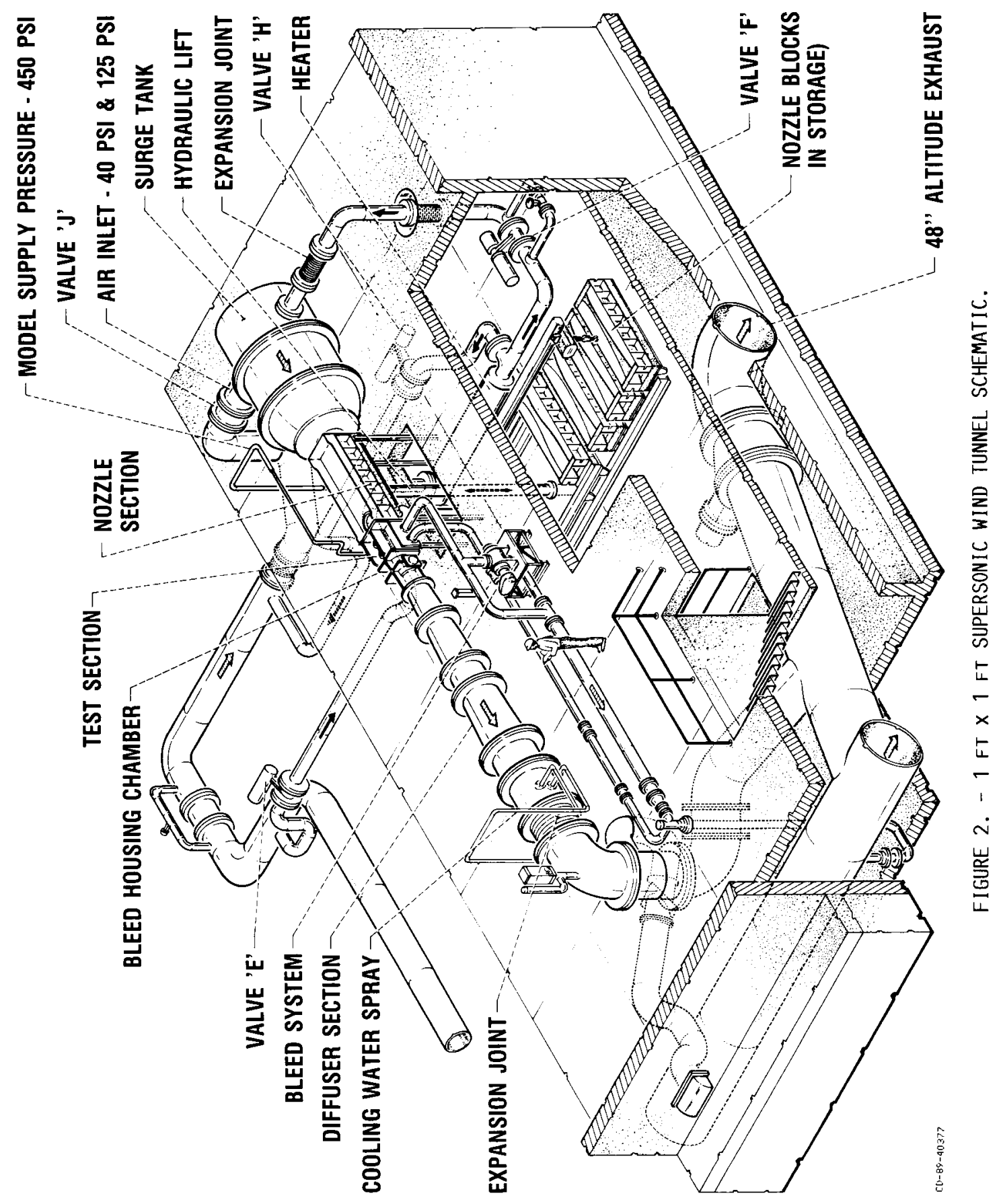


BLACK AND WHITE PHOTOGRAPH

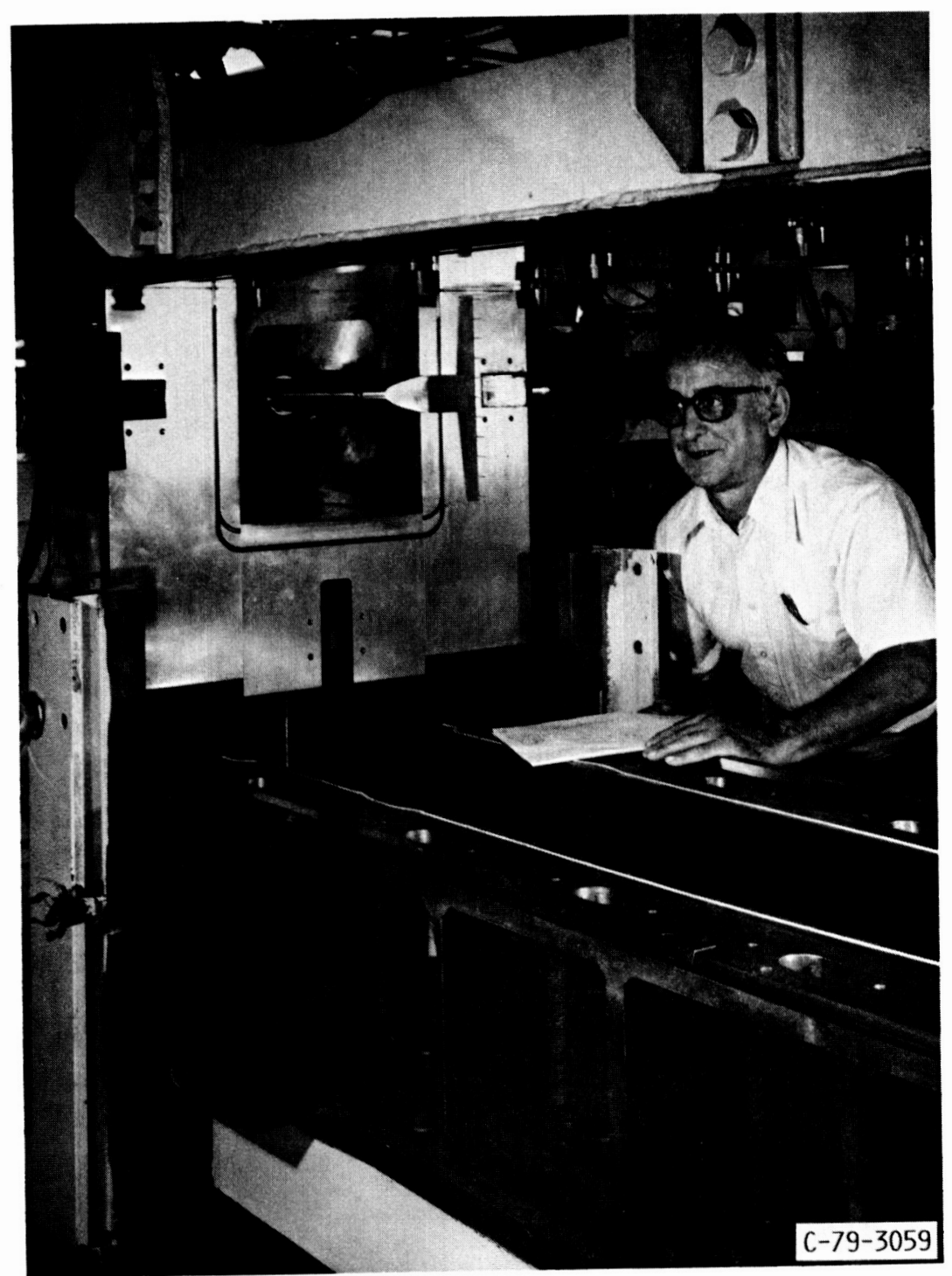

FIGURE 3. - 1 FT BY 1 FT SUPERSONIC WIND TUNNEL TEST SECTION. 


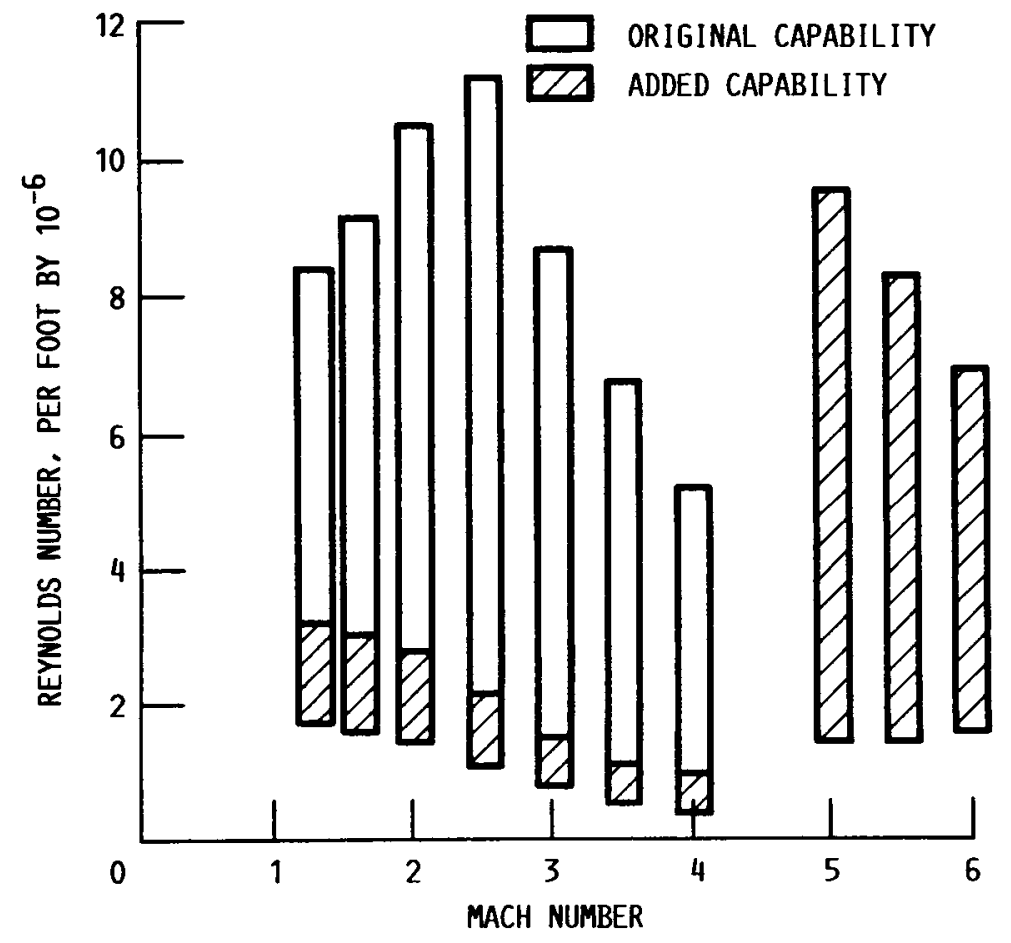

FIGURE 4. - 1 FT BY 1 FT SUPERSONIC WIND TUNNEL OPERATING ENVELOPE. 
BLACK AND WHITE PHOTOGRAPH

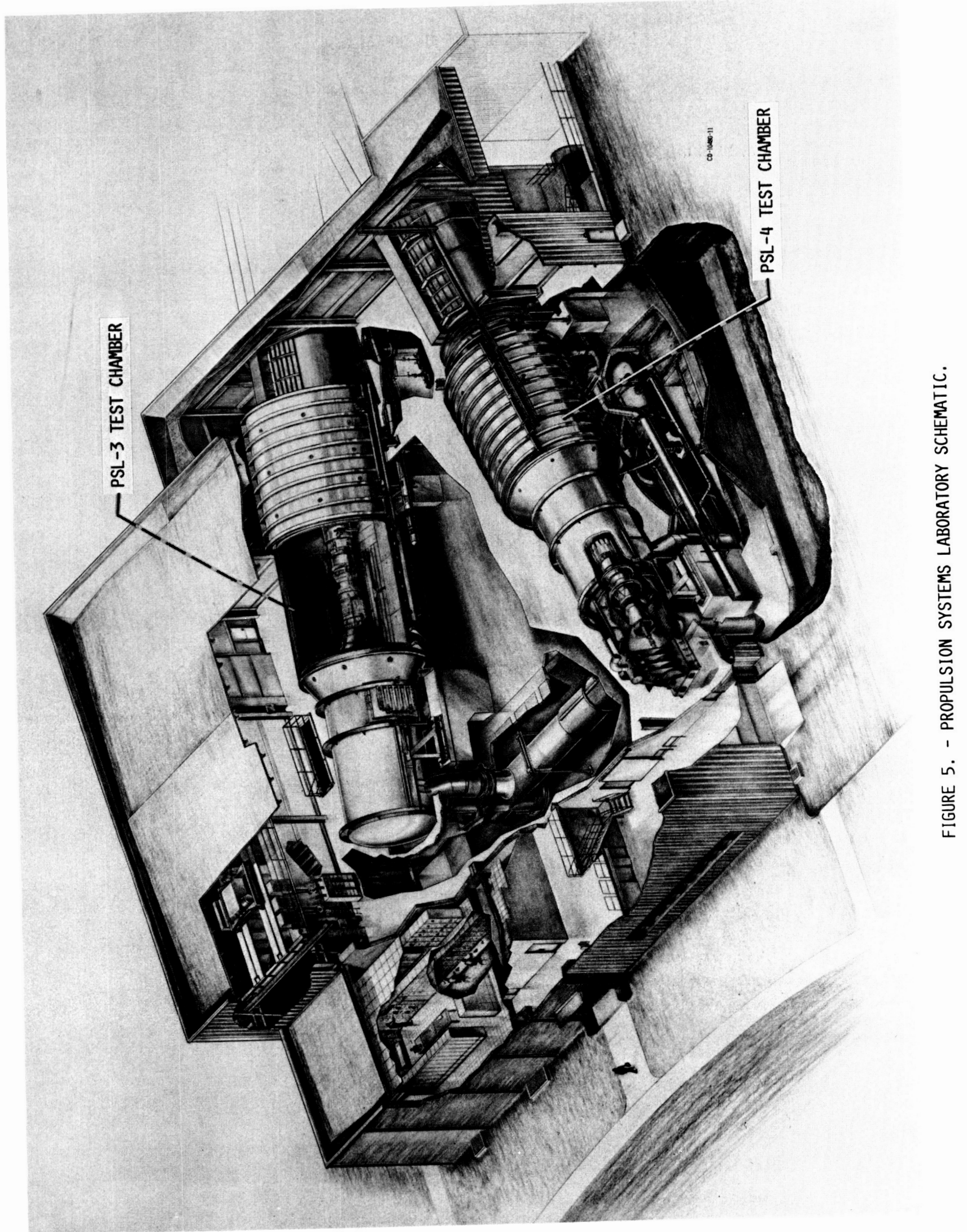




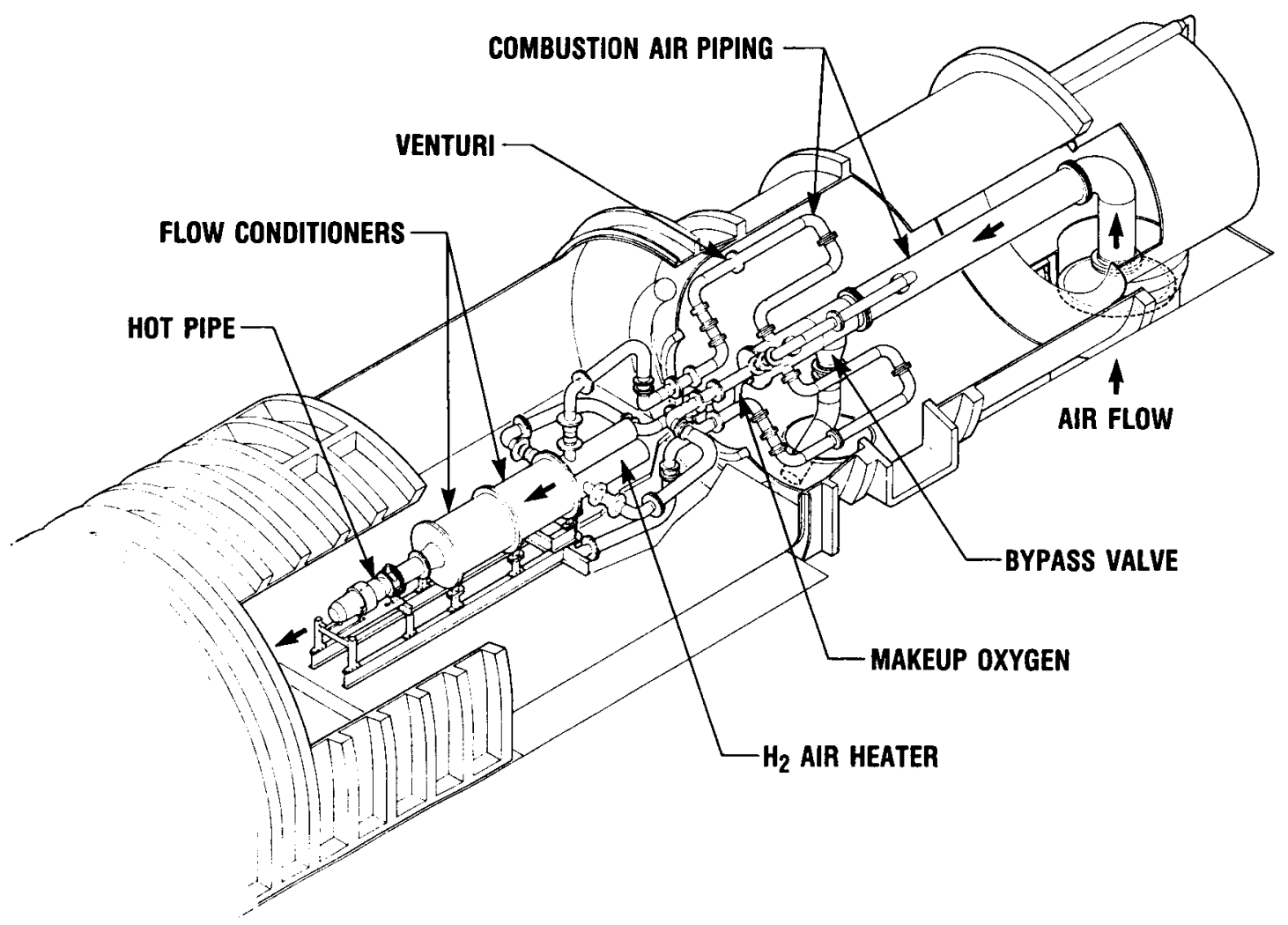

FIGURE 6. - PSL-4 DIRECT-CONNECT MODIFICATIONS.

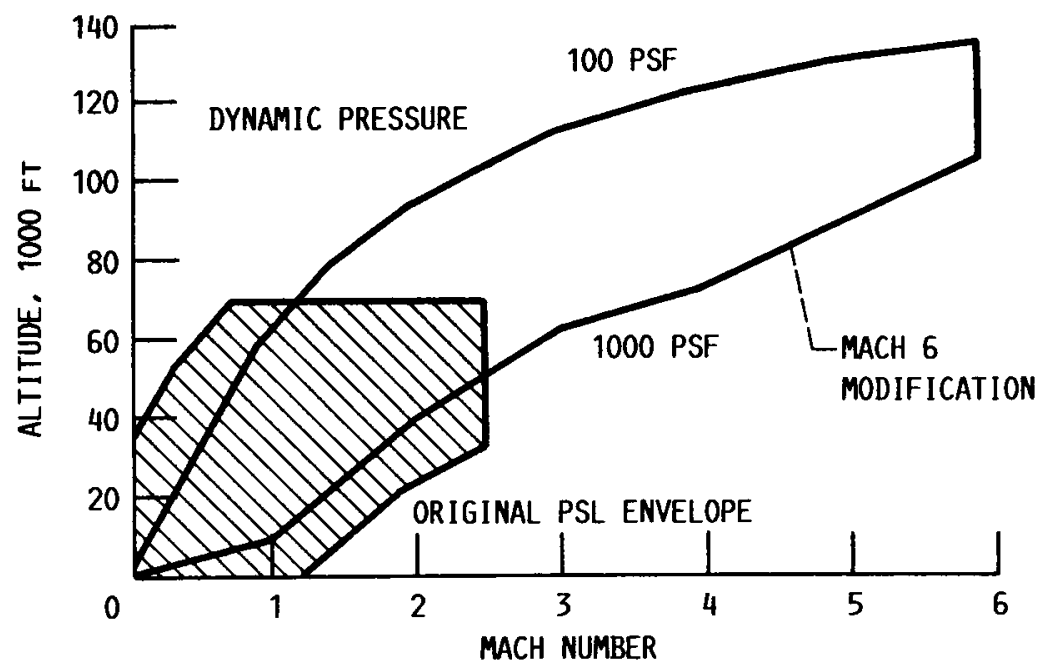

FIGURE 7. - PSL OPERATING ENVELOPES. 


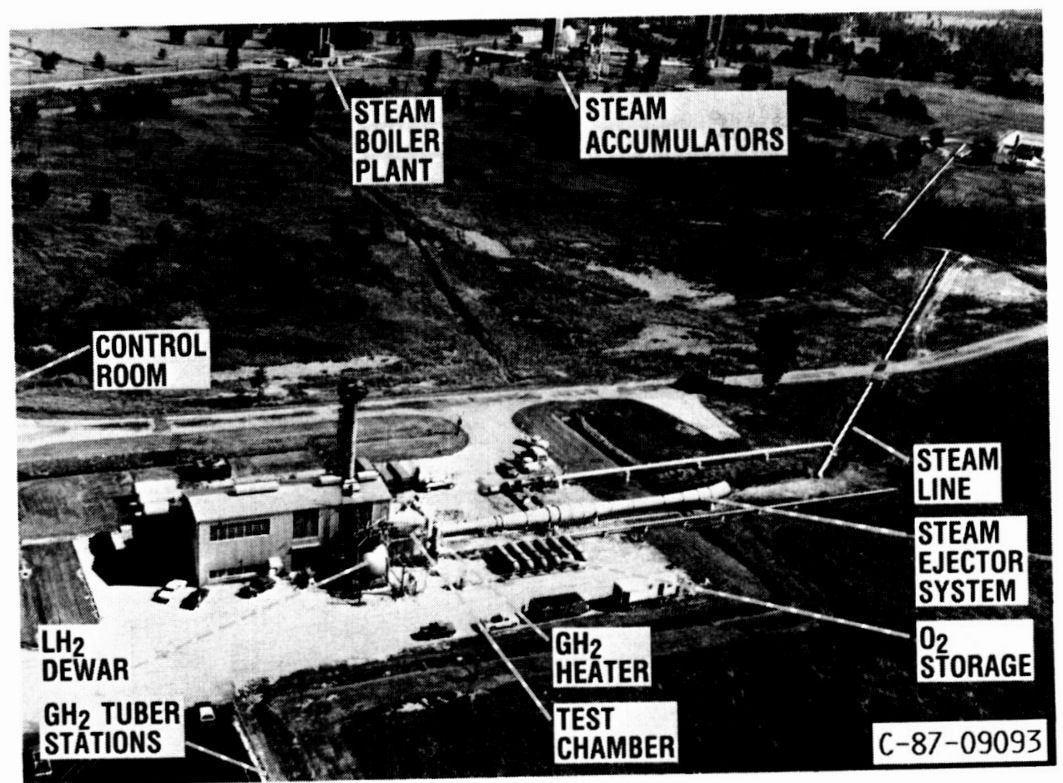

FIGURE 8. - HTF AERIAL VIEW.

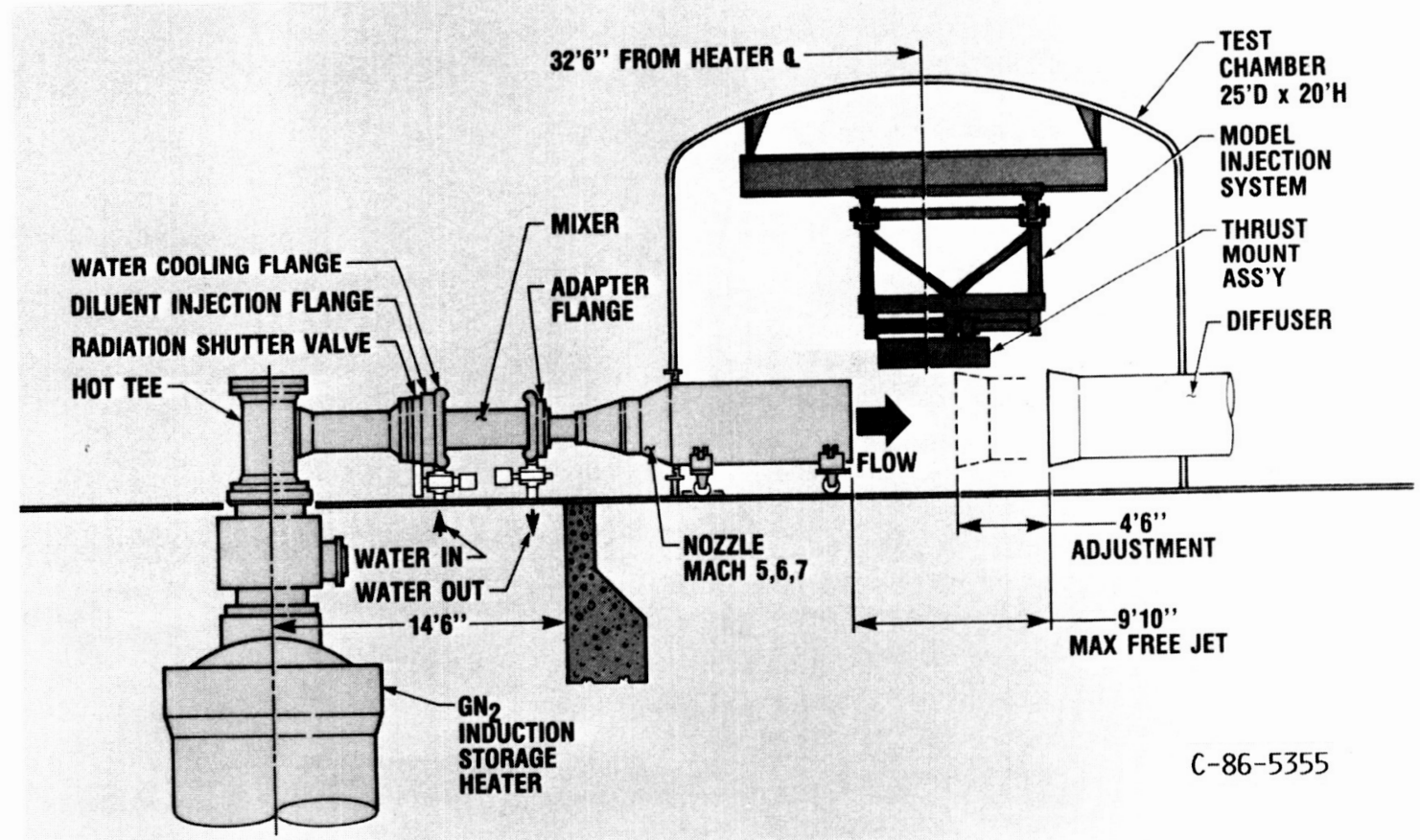

FIGURE 9. - HTF SCHEMATIC VIEW. 


\section{ORIGINAL PAGE \\ BLACK AND WHITE PHOTOGRAPH}

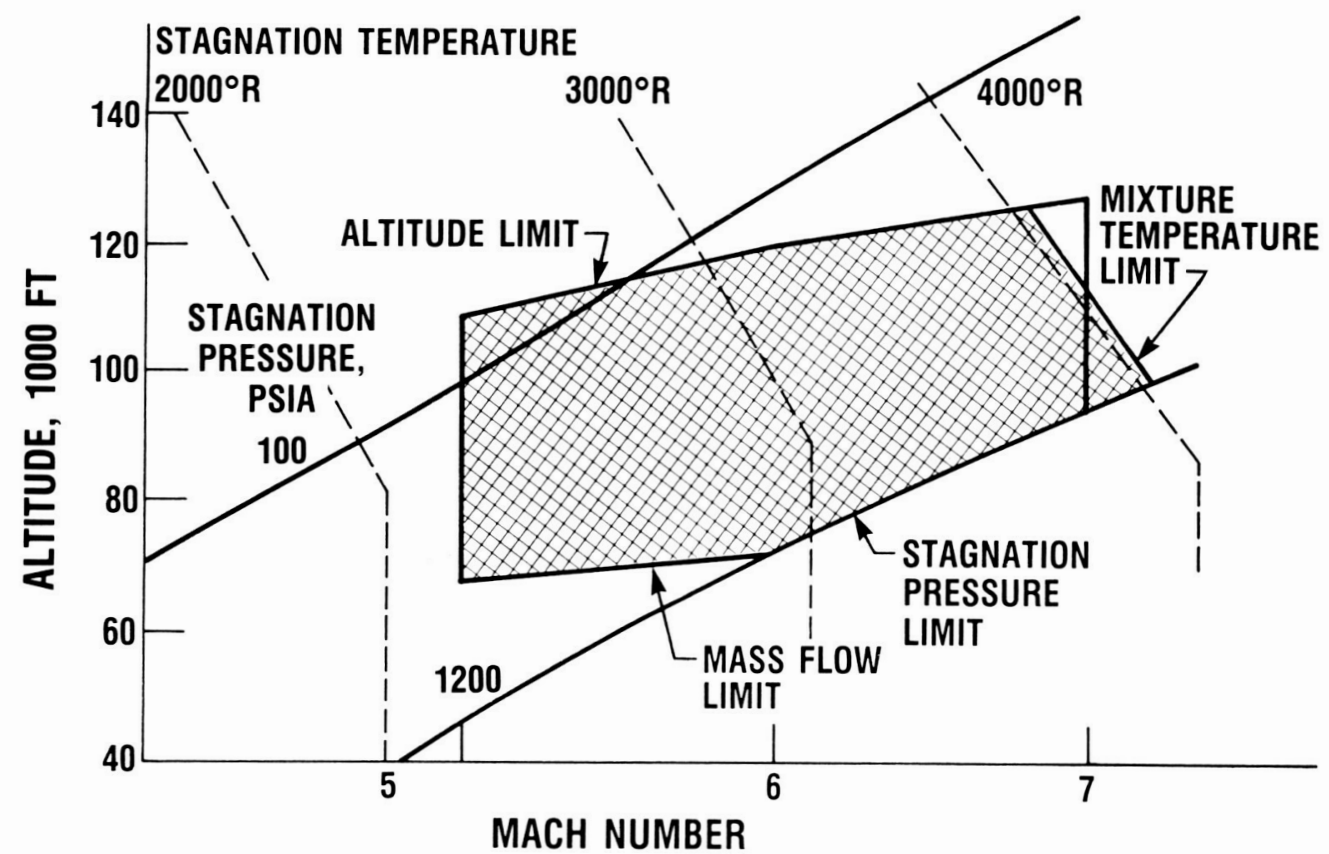

FIGURE 10. - HTF OPERATING ENVELOPE.

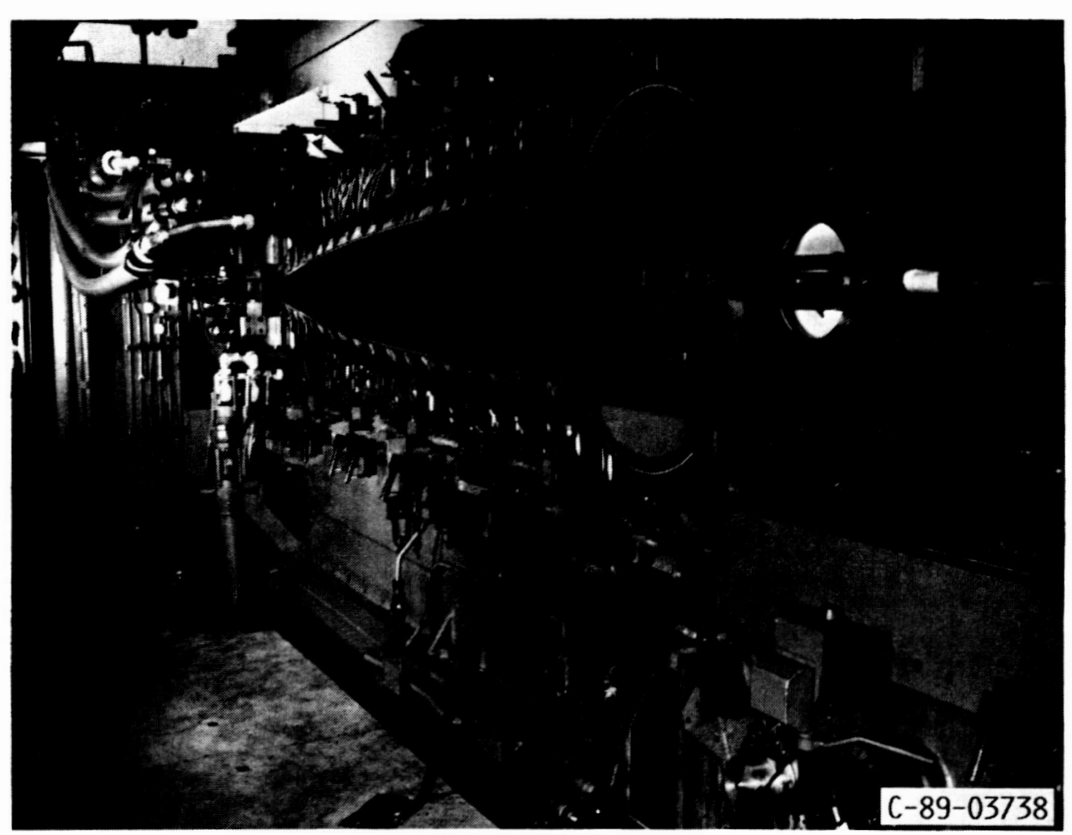

FIGURE 11. - 21 IN. HYPERSONIC WIND TUNNEL NOZZLE AND TEST SECTION. 


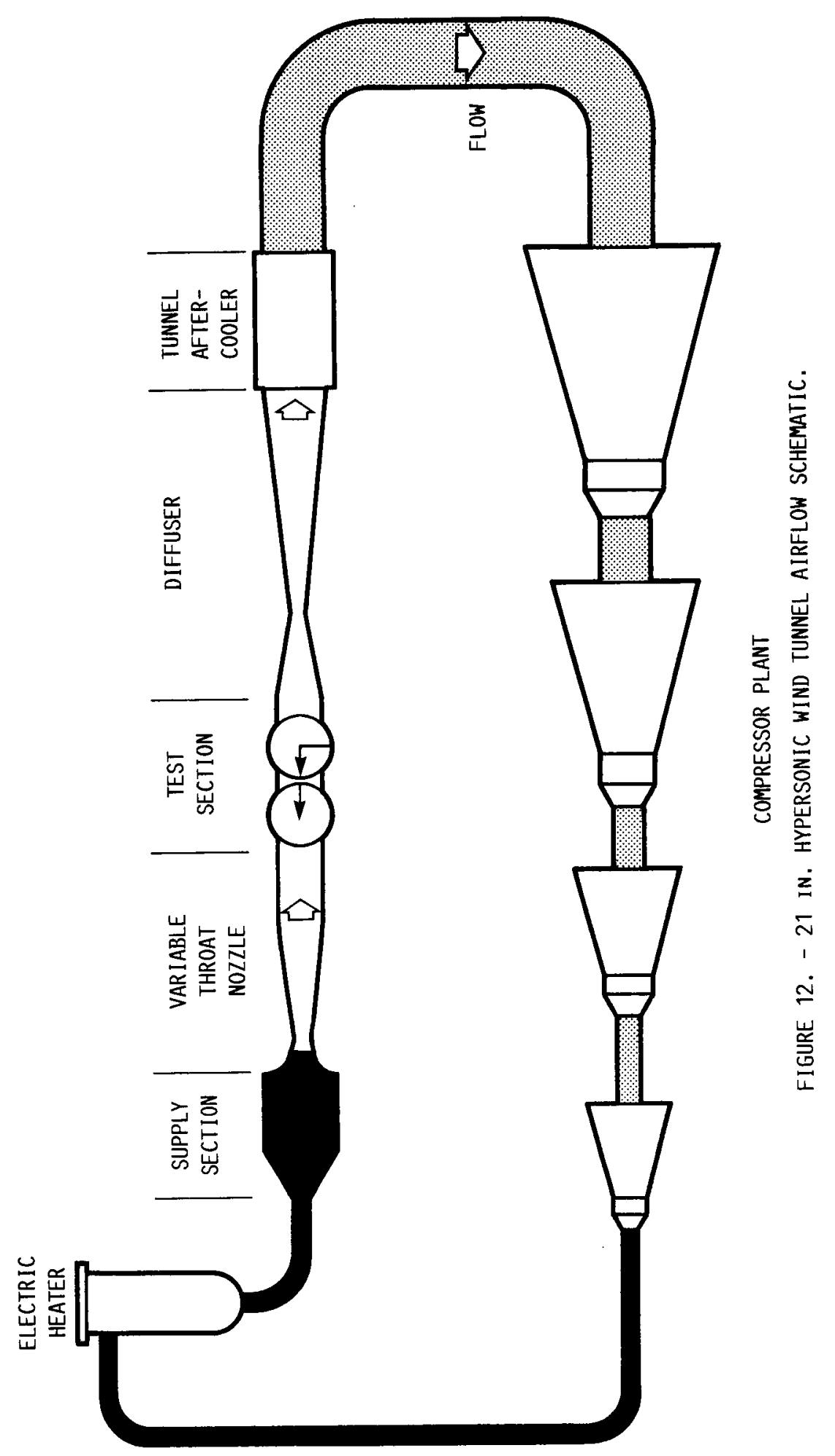




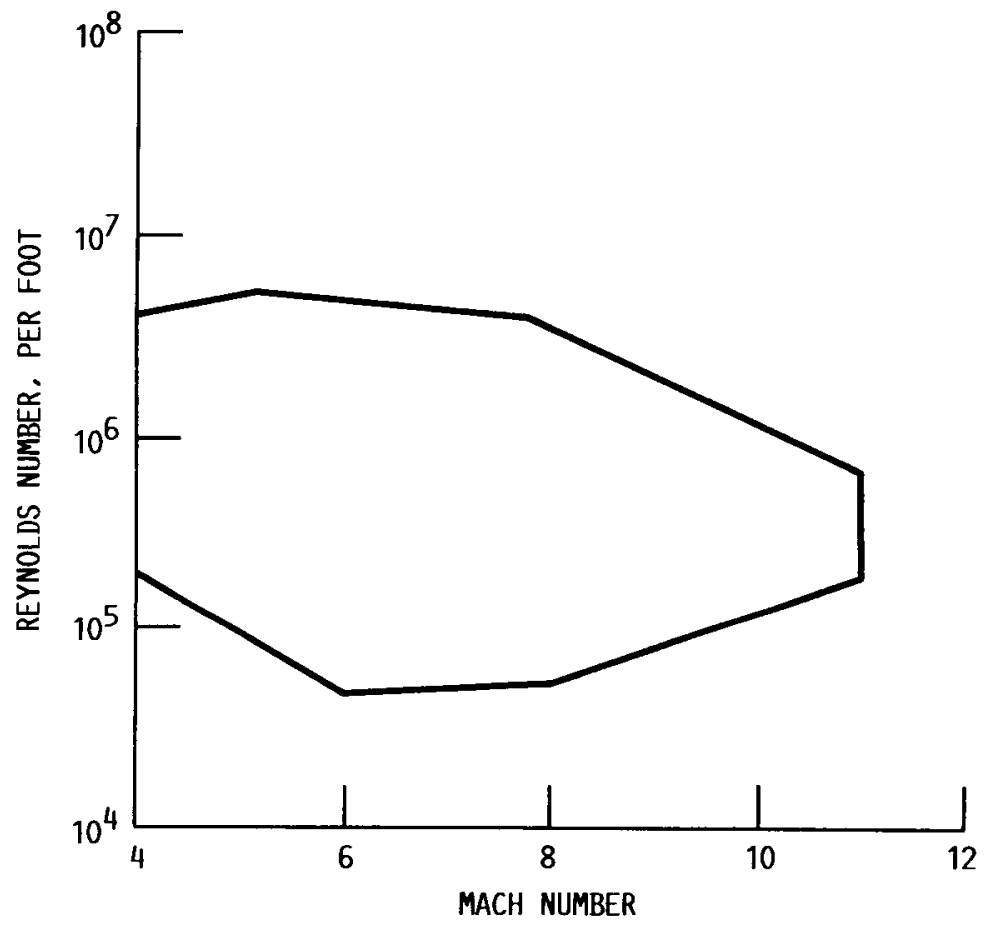

FIGURE 13. - 21 IN. HYPERSONIC WIND TUNNEL OPERATING ENVELOPE. 


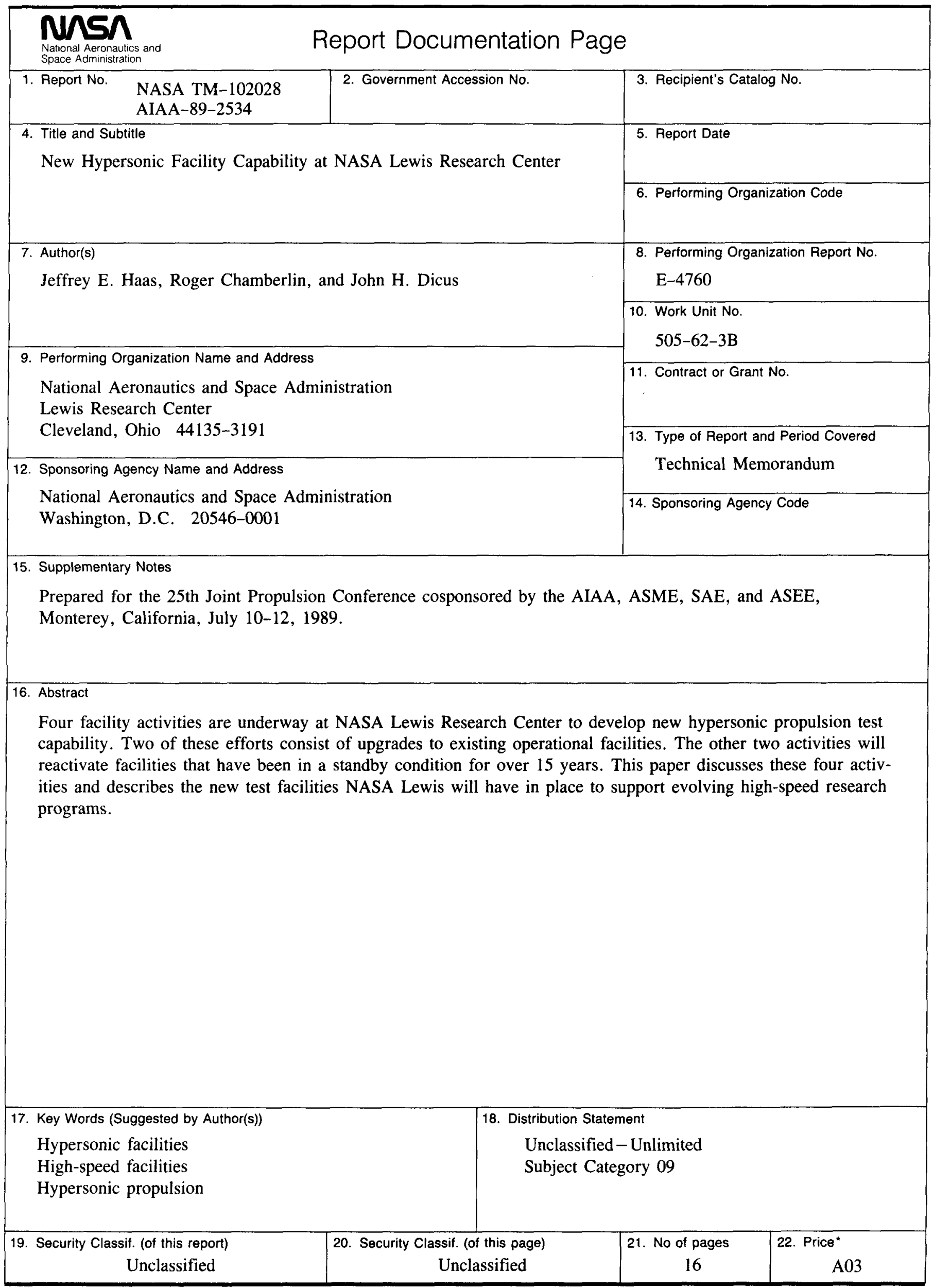

